\title{
STRATEGIES USED BY PHYSICAL EDUCATION TEACHERS TO ENHANCE PROFESSIONAL WELL-BEING
}

\author{
Sacha Stoloff, \& Julien Glaude-Roy \\ Department of Human Kinetics, Université du Québec à Trois-Rivières/Groupe interdisciplinaire de \\ recherche appliquée en santé (Canada)
}

\begin{abstract}
Disengagement from the teaching profession is a contemporary scourge among Canadian teachers. Quebec province is experimenting the same problematic situation. Diverse impacts are noticeable, associated to public costs, professional wearout, exhaustion and burnout. This research invites to an ideological and scientific shift in order to shed light on teachers' professional well-being. Positive psychology is used as theoretical framework to address the phenomenon, and better understand "What strategies do teachers use to create, maintain or restore a state of well-being?". To this end, the research objective is to draw a portrait of the different strategies used by teachers in order to enhance well-being. As a first stage of the project, the research protocol is aimed at teachers in physical education and health, since they are now recognized as leaders, models and promoters in healthy lifestyles in schools and communities. At the methodological level, we have undertaken five focus groups with 37 teachers, representing seven different regions of Quebec. The results will allow us to propose two avenues of strategies used by PE teachers in relation with Self and with Others. It is in this unprecedented perspective that we aspire to value the profession and the teachers, to favor the pursuit of professional careers and the motivation of teachers, and consequently to promote the educational success of pupils.
\end{abstract}

Keywords: Strategies, professional well-being, teacher, positive psychology.

\section{Introduction and objectives}

Psychological health is divided in two poles: psychological well-being, as the affirmation of a healthy mental state, and psychological distress, as being the affirmation of a mental health problem (Stamate, Brunet \& Savoie, 2015). In teaching, psychological distress has been studied and broadcasted, facilitating knowledge advancement and a better understanding of distress and ill-being phenomenon. Disengagement from the teaching profession is one of the contemporary scourges among Canadian teachers (Kamanzi, Barroso Da Costa \& Ndinga, 2017), and Quebec province is experimenting the same problematic situation (Karsenti, Correa Molina \& al., 2015). Diverse impacts are noticeable, associated to public costs (MEES, 2018), professionnal wearout (Lantheaume \& Hélou, 2008), exhaustion and burnout (Houlfort \& Sauvé, 2010).

However, an ideological shift has been established over the last ten years to complement this knowledge. Indeed, the search for positive feelings is increasingly tackled and valued in teaching, with concepts emerging such as pleasure (Brassell, 2015), passion (Brunelle \& Brunelle, 2012), leadership in teaching (Wilmore, 2007), or flow (Csikszentmihalyi, 2008). Thus, in order to better understand the optimal functioning at work (Seligman, 2011), the integrative concept of professional well-being becomes an approach used in teaching to comprehend how a person is able to attein achievement according to his full potential (Goyette, 2014, 2016, Stoloff, Boulanger \& al., 2018). The result of professional well-being is a sense of accomplishment and positive emotions, which tend to limit distress and disengagement at work (Seligman, 2011).

Even at an early stage, new scientific advancements have demonstrated the value of this approach (Theorêt \& Leroux, 2014). However, it is noted that even when the research approach addresses a positive aspect (well-being, job satisfaction, self-determination, etc.), the majority of research results present a lack of well-being at work, lack of satisfaction at work, problems limiting the satisfaction of basic needs, etc., denoting a rooted scientific culture addressing problems where few real transformations are observed.

To initiate a change, the research question of this article relates to specific teacher's practices enhancing well-being: How do some teachers live a state of professional well-being and cope with the difficulties of the profession? To this end, the research objective is to draw a portrait of the different strategies used by teachers in order to enhance well-being. As a first stage of the project, the research protocol is aimed at physical education (PE) teachers, since they are known to be leaders, models and promoters of healthy lifestyles in schools and communities, especially in Quebec (MEQ, 2001). 


\section{Conceptual framework}

Based on solid theoretical grounds, positive psychology theory enables a better understanding of the source of well-being and the means to achieve it (Seligman, 2011). It is a bold epistemological position that offers a constructive angle for proposing educational and flexible means of action that teachers can implement and adapt.

To this day, there seems to be no consensus on a definition of well-being, since it is a multidimensional concept, mainly studied in positive psychology, which contributes to an individual's positive construction about his life (Della Fave, 2011). Here, "The topic is a construct - well-being which in turn has several measurable elements, each a real thing, each contributing to well-being, but none defining well-being" (Seligman, 2011, p.15). To this end, Seligman's (2011) PERMA model presents five elements that characterize well-being: Positive emotions, Engagement also described as flow, positive Relations, Meaning, and Accomplishment. Far from monism, these five elements comprise what people will "feel" in a state of well-being.

\section{Method}

Five focus groups with 37 teachers where undertaken, representing seven different regions of Quebec (Abitibi-Témiscamingue, Capitale-Nationale, Estrie, Lanaudiere, Laurentides, Laval, and Outaouais), favouring the diversity of "contextual" responses. Interviews focused on indicators of well-being and strategies used to create, maintain or restore a state of well-being. The content analysis was conducted according to themes (Paillé \& Mucchielli, 2008) using NVivo10 software. In order to limit theoretical influence, the induction was insured by analysists new to the concept, unaware of any well-being definitions, frameworks, or models. This approach privileged theme emergence related directly to content. Intercoder reliability was $92 \%$ of the initial coding (Deslauriers, 1991); inconsistencies were then recoded until an intercoder agreement was reached.

\section{Findings}

Results present five main strategies that emerge from the analysis made of these teachers' speeches, and the means to make these strategies effective. Two avenues of strategies were used by PE teachers in relation with Self (Strategies 1 to 3 and 5) and in relation with Others (Strategy 4).

The first strategy is to put things into perspective, and is initiated by taking a step back from a difficult situation to see the overall picture and understand the different issues. Then, to ensure an adequate portrait, rationalizing makes the analysis of the situation as objective as possible by limiting emotional reactions. In turn, this enables oneself to relativize, accept or just let go of any stress caused, change the reachable, and from there, be flexible and open to different perspectives.

The second strategy is optimism, and is done by putting oneself in a positive mental disposition, keeping in mind that all experiences can be sources of learning or new understanding. From there, consider the resolving sequel from a solution perspective rather than a problem solving one. This strategy is nourished by a constructive Being, working with motivating and realistic goals or projects, or stimulating and successful content.

The third strategy is proactivity and comes in two stages. The first stage is to act in anticipation by preventive organization of one's environment. It is about predicting, planning, and organizing the elements on which one has control; to master one's premises and contents. The second step is related to those around us. Here, it is a question of being involved in the school's dynamics, on a small to large scale, by engaging and participating in activities and projects that are initiated or offered. Conversely, it's also about renouncing to activities that don't feed us anymore.

The fourth strategy is networking, and is related to the potential and strength of the group of people involved in the network. For this, three levels emerge. The first level is primarily the creation of positive relations, which requires getting to know others and then, accepting and appreciating the differences. It is easier to get along with those who resemble us. Creating a positive relationship with those who are different can require a more structured and conscientious approach rather than an instinctive one. Quality relationships are then built on people's strengths rather than their irritable sides. The second level is, once the positive relation is established, to communicate with those who are willing to listen, and ask for help when needed. The third level of this strategy is to accept or initiate collaboration and share, to create professional stimulation and avoid possible isolation.

The fifth strategy is to take responsibility, therefore, to be convinced that we have control over situations, because we make our choices. We can decide to stay, to leave, to change, to keep, to adjust, or to question all the professional elements that affect us. Taking responsibility for our choices and taking control over situations is giving oneself the opportunity to experience flow. To do this, all necessary ingredients are put in place, to our liking, to be able to abandon oneself in the moment, and be absorbed in the moment. 


\section{Conclusion}

All five strategies described by PE teachers to enhance professional well-being seem to emerge from self and the impact on others. This is to say that one must have the strength and the tools to take control over situations, in a positive and rational manner. Having said that, more research is necessary to enrich knowledge addressing strategies used by others (school board members, mentors, leaders, etc.) to cultivate a positive school climate and well-being in others. It is in this unprecedented perspective that we aspire to value the profession and the teachers, to favor the pursuit of professional careers and the motivation of teachers, and consequently to promote the educational success of pupils.

\section{Acknowledgements}

The authors wish to thank the Fonds de Recherche du Québec: Société et Culture and the Groupe Interdisciplinaire de recherche en Santé Appliquée for their financial support.

\section{References}

Brassell, D. (2015). Cultiver le plaisir d'enseigner. Montréal: Chenelière Éducation.

Brunelle, J-P., \& Brunelle, J. (2012). Susciter la passion pour les activités physiques et sportives. Sherbrooke: Philia.

Csikszentmihalyi, M. (2008). Flow: The psychology of optimal experience. New York: Harper perennial.

Della Fave, A. (2011). Psychologie Positive. Un parcours difficile entre idéal et réalité. Dans C. Martin-Krumm, \& C. Tarquinio (Éds.), Traité de psychologie positive. Bruxelles: De Boeck.

Deslauriers, J-P. (1991). Recherche qualitative: Guide pratique. Montréal: McGraw

Goyette, N. (2014). Le bien-être dans l'enseignement : étude des forces de caractère chez des enseignants persévérants du primaire et du secondaire dans une approche axée sur la psychologie positive. (Thèse de Doctorat inédite).

Goyette, N. (2016). Développer le sens du métier pour favoriser le bien-être en formation initiale à l'enseignement. Revue canadienne de l'éducation, 39(4), 3-30.

Houlfort, N., \& Sauvé, F. (2010). Santé psychologique des enseignants de la Fédération autonome de l'enseignement. Montréal : École nationale d'administration publique.

Kamanzi, P., Barroso da Costa, C., \& Ndinga, P. (2017). Désengagement professionnel des enseignants canadiens: de la vocation à la désillusion. Une analyse à partir d'une modélisation par équations structurelles. McGill Journal of Education/Revue des sciences de l'éducation de McGill, 52(1), 115-134.

Karsenti, T., Correa Molina, E. A., Desbiens, J.-F., Gauthier, C., Gervais, C., Lepage, M. ..., \& Collin, S. (2015). Analyse des facteurs explicatifs et des pistes de solution au phénomène du décrochage chez les nouveaux enseignants, et de son impact sur la réussite scolaire des élèves Rapport de recherche, programme actions concertées. Fonds de recherche Société et culture.

Lanthéaume, F., \& Hélou, C. (2008). La souffrance des enseignants. Une sociologie pragmatique du travail enseignant. Paris : PUF.

Ministère de l'Éducation du Québec [MEQ]. (2001). Programme de formation de l'école québécoise. Éducation préscolaire, enseignement primaire. Québec : Gouvernement du Québec.

Paillé, P., \& Mucchielli, A. (2008). L'analyse qualitative en sciences humaines et sociales. Paris: Armand Colin.

Seligman, M. (2011). A visionary new understanding of happiness and well-being: Flourish. Toronto: Atria.

Stamate, A-N., Brunet, L., \& Savoie, A. (2015). La compétence en emploi peut-elle prédire la santé psychologique des enseignants? Le travail humain, 4(78), 355-378.

Stoloff, S., Boulanger, M., Glaude-Roy, J., Miquelon, P., \& Rivard, M-C (2018). Professional well-being: the point of view of physical education teachers. Dans M. Carmo, Education and New Developments 2018, pp.412-414. Lisbon: InPress Science.

Théorêt, M., \& Leroux, M. (2014). Comment améliorer le bien-être et la santé des enseignants? Des ressources pour la résilience éducationnelle. Louvain-la-Neuve, Belgique : De Boeck.

Wilmore, E.L. (2007). Teacher leadership. Thousand Oaks: Corwin Press. 